\title{
Social Media Based STEM Enrichment Curriculum Positively Impacts Rural Adolescent Health Measures
}

\author{
Ann Chester', Sara Hanks², Summer Kuhn', Floyd Jones ${ }^{1}$, Travis White ${ }^{3}$, Misty Harris ${ }^{1}$, \\ Bethany Hornbeck', Sherron McKendall', Mary McMillion', Cathy Morton', Mallory Slusser', and R. Kyle Saunders'
}

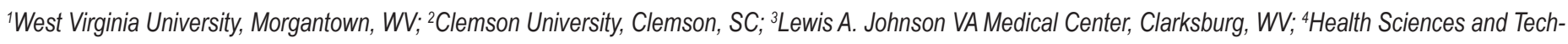
nology Academy, Grafton, WV

Keywords: STEM Outreach, Social Media, Prevention, Adolescent, Rural

DOI: https://doi.org/10.15695/jstem/v1i1.17

\begin{abstract}
Some STEM outreach programs connect students to real-world problems and challenge them to work towards solutions. Research shows one-third of children between ages 5-17 in the U.S. are overweight. Socioeconomic status, race, and parental educational attainment all influence this issue as well as living in a rural or urban area. A rural high school STEM outreach program used a social media curriculum focused on healthy lifestyles and measured impact on the health of adolescents from these backgrounds. Health screenings and college mentors were provided to 134 adolescents from 26 counties in WV. The social media intervention lasted seven months with participants using near-peer and mentor support to achieve personal health goals set at the initial health screening. The results of pre- and post-intervention health screenings were compared for any changes in health measures by student goal and participation. BMI decreased significantly in the group of participants who selected a weight loss goal, while those choosing to improve their nutrition significantly increased healthy cholesterol levels. A positive impact was seen on adolescent health outcomes through linking a high school STEM outreach program with a higher education institution to deliver STEM enrichment curriculum through social media.
\end{abstract}

\section{INTRODUCTION}

Science Technology Engineering and Math (STEM) outreach programs have had success in increasing interest in STEM, increasing college readiness and increasing diversity in STEM (National Academy of Sciences, 2015). One outreach program, Health Sciences and Technology Academy (HSTA), has connected scientists with hard-to-reach populations to study health issues (Siciliano et al., 2018). The success of this experience led the STEM outreach program to develop curriculum to help with prevention and address chronic health issues. This research paper describes a pilot study investigating the potential of outreach programs to design curriculum to help high school students become effective health influencers for improving lifestyles among themselves as they learn how to conduct research.

HSTA Description. HSTA is a mentoring program in the state of West Virginia that helps underrepresented high school students enter and succeed in STEM-based undergraduate and graduate degree programs. HSTA marshals the efforts of hundreds of mentors, teachers, community members, higher-education faculty and staff, and the HSTA participants themselves through a framework that supports students facing social and financial challenges to obtain a diploma and further their education.

Since its inception in 1994, the program has grown from nine teachers serving 44 students in two West Virginia counties to a network of 80 teachers serving approximately 800 students across the state. HSTA participants are primarily students who have grown up in rural communities and are first in their families to attend college. More than half are financially disadvantaged, and one-third are African American. The vast majority of HSTA graduates obtain a college education and many earn advanced degrees. Implemented through West Virginia University (WVU), HSTA's main goals are to increase college attendance in Appalachia, improve STEM education in public schools, empower communities through youth leadership, and increase the number of health-care providers and STEM educators in underserved communities (Chester and Dooley, 2011; McKendall et al. 2014)

The HSTA program puts rigorous academic expectations into place that connect learning to students' personal expe- 
riences. It rewards participants and teachers with generous incentives that recognize their accomplishments, and it offers through the support of the West Virginia Legislature and state colleges and universities substantial tuition waivers to successful participants who attend an in-state institution for an undergraduate or STEM-based graduate degree.

HSTA's accomplishments in West Virginia are exceptional (Chester and Dooley, 2011; McKendall et al., 2014). Without this far-reaching mentoring program, thousands of students would not realize their unique potential or use their abilities to improve the communities from which they come. As of December 2017, HSTA high school graduates numbered 2556 with $99 \%$ going to college, and HSTA college graduates have earned 939 bachelors' degrees, 225 masters' degrees, and 95 terminal degrees. Well over half obtain STEM degrees (62\%), and the majority stay in West Virginia to work $(84 \%)$.

Community ownership is a distinctive feature of this program. The local governance of HSTA resides with local volunteers in the 14 different HSTA regions across the state. The volunteer boards are comprised of at least one leader from an underserved community, an educator, a health care provider, a current HSTA parent and a HSTA student. These regional boards are provided with funds and the power to hire a local coordinator and teachers to carry out the HSTA curriculum according to the policies and procedures defined by a state-wide governing board. The state-wide governing board oversees the entire HSTA program through its director and staff. This board is structured to ensure that local rep- resentation is over $51 \%$. The remaining seats on the statewide governing board are filled by colleges and universities, state board of education and Area Health Education Center leadership. The fact that over $51 \%$ of the votes are held by community volunteers engenders the feeling of community ownership. While the HSTA state board ensures that policies and procedures are followed in line with the HSTA mission, the regional boards ensure that problems are handled at the lowest possible level without interference from an authoritarian outsider who may not truly understand the nuances of the local situation.

Students enter HSTA the summer before 9th grade (Figure 1). HSTA staff recruit potential participants through presentations at local schools and community organizations, churches, traditional media, social media, and other outreach efforts. Interested students submit applications that are approved or denied by the local governing board that oversees each applicant's home region. Potential participants are vetted on need, potential to succeed, and interest in STEM careers. They must also meet at least one of four eligibility criteria: African American, rural, financially disadvantaged (free or reduced-price lunch), and/or first-generation to college (neither parent holds a college degree). Most students meet two or more of these criteria. Of the students currently enrolled in the program, $37 \%$ are African American, $46 \%$ are financially disadvantaged, $68 \%$ are first generation to college, and $75 \%$ are rural. Although gender is not a criterion for admission, $69 \%$ of HSTA's students are female.

HSTA students matriculate through the program in grades

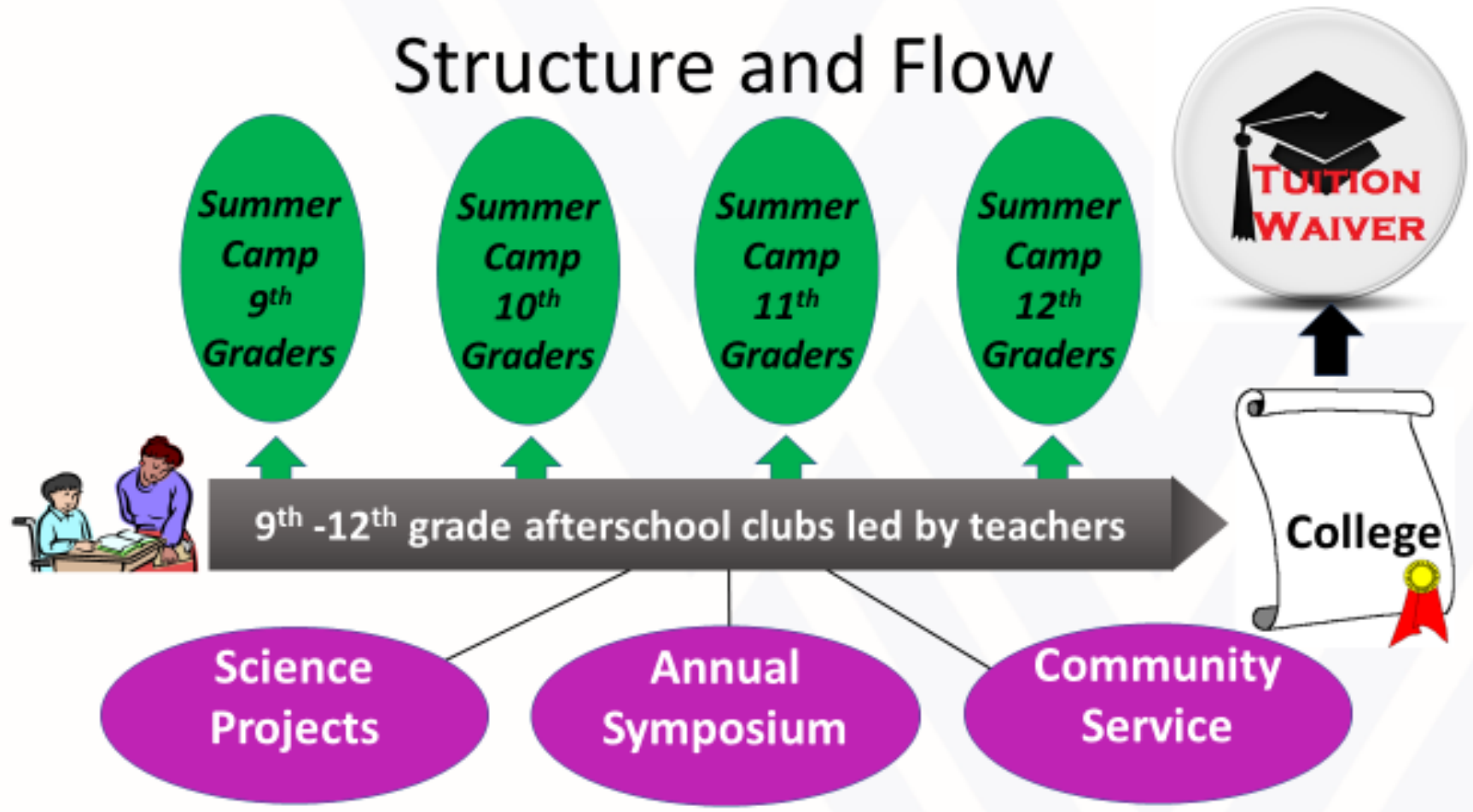

Figure 1. Health Sciences and Technology Academy student pipeline to college and STEM majors. 
9-12. After-school clubs meet for 24 hours each semester and grade-specific summer camps occur every summer, with each camp building understanding of the research process and enriching the students' understanding in STEM areas. HSTA requires a 2.5 GPA for acceptance and a 3.0 GPA for continuation in the program (grades 10-12). To complete the program, students must participate in their local HSTA after-school club and achieve a $70 \%$ attendance rate per semester, complete four research projects (one per year) and present their results at HSTA's annual Science Symposia, attend two HSTA summer camps, complete 75 hours of community service, and adhere to all behavioral policies.

Philosophy of the HSTA Curriculum. As a nation, we are long past the time when learners were adequately equipped to create their futures with facts they learned in school. To successfully operate today an individual or team must be able to accurately identify and limit a problem, develop possible solutions to that problem and conduct fact-based research of those possible solution pathways. The challenge for students now is to know how to winnow the plethora of facts available for accuracy and usefulness and to use those selected as starting points for solving problems.

The foundation of HSTA curriculum is not subject or content driven. Instead it is based on core elements known as the seven Rs described below:

1. Reward: If HSTA students complete all requirements, a college tuition waiver is their reward. It's the hook that gets them into HSTA and a major ingredient of their success in graduating from HSTA and high school and attending college.

2. Recreation: If HSTA is not fun, students don't stay in. HSTA has created a unique learning environment that captures student engagement through hands-on problem-solving activities, challenging learners while keeping their interest with levity and shared hard work. The foundation of science is problem-solving; the challenge of drawing youngsters into the scientific arena is to replace common misperceptions of young learners that science is hard. HSTA carefully selects activities that show club members that science is fun, without watering down prescribed methodologies. HSTA makes sure its substantive college preparatory activities are fun hence Recreation is key.

3. Relationships: HSTA is not a requirement for growing up or graduating. It is an optional activity. HSTA students need relationships to help them break out of the social and environmental constrictions that brought them into the program in the first place. Humans are social creatures with a need for human contact and support from a human network to which they feel a sense of belonging. It is important for HSTA students to have friends with the same goals and aspirations, have near-peer friends that are like them but have already been successful, and supportive relationships with people that are not necessarily like them who support them with resources and opportunities.

4. Research: Research is the platform HSTA uses to teach college readiness for a STEM major. By engaging in replicable scientific research, students learn: to reason using linear thinking; to take an in-depth look at their communities to identify problems; to conduct background inquiry; to formulate testable questions; to test for solutions by engaging in scientific inquiry using science and math concepts and specialized skills (e.g., data collection, using microscopes and other laboratory equipment, performing experiments, conducting evaluations, statistics, etc.); to synthesize their findings from the evidence they collect; and to communicate their findings to others.

5. Relevance: According to Brown et al. (1989) knowledge acquisition depends on the contexts and activities from which it is gained. Learning occurs when students process new information in a meaningful way that makes sense within their own frames of reference. HSTA connects students with meaningful content through research projects centered upon their communities and areas of personal interest. The research projects are still arduous but the students care about what they are doing. Personally engaged students remember what they learn (Buijs and Admiraal, 2013) and personally engaged HSTA students discover that they can directly address important community issues (Siciliano et al., 2018). HSTA has found that students, armed with information and interest, can partner with local entities and move their communities toward solutions to long-standing issues of local concern. These entities range from county extension agents to work on bully-free schools, to physicians doing research on osteoarthritis and increasing awareness to the benefits of movement and weight loss on pain reduction, to local grassroots efforts to grow fresh vegetables in year-round green houses on school property in food deserts. The great majority of HSTA alumni (84\%) come back to West Virginia to live and work continuing this relevant community connectivity in high school.

6. Rigor: Scaffolding of the project evaluation form from Students and Research, (Cothron et al., 2006), was used to sculpt an HSTA rubric. This rubric is used to measure the mechanics of each student research project as it is conducted and prepared for presentation. In addition, the rubric measures student understanding of their research, as well as relatability and impact on the community. For instance, students begin with an observation and start to develop questions about their observation/topics. They look at the community needs, determine what questions are researchable and measurable, and then develop the focus of their research project. These are scored items, and students discuss these when they present. Community Relevance and Question are examples of two of the 12 sections of the rubric worth a total of 56 possible points. Other sections include justification 
and background research, hypotheses, variables, procedures, results, data analysis, conclusion, references and overall presentation skills. Every student must pass a certain level to advance to the next year. That rigor level never changes. The freshmen have much more assistance in reaching that level with support from their teachers, HSTA staff, and the older students in their clubs. As students matriculate and become more confident, the hand-holding decreases and by their senior year, most students are helping the younger ones just as they were helped when they entered the program. Meanwhile, each year the students see incremental sophistication of their research. By their senior year, they are college ready.

7. Repetition: Once is not enough. Everyone needs repetition to attain mastery. Over the four years of HSTA, students are often progressing from performing below mastery level to well above mastery (Chester, in preparation). Below mastery level proficiency upon entry into HSTA is most likely due to lack of opportunity prior to HSTA, not lack of potential.

This philosophy and infrastructure have been in place for 24 years, allowing for testing of creative ways to enhance the student experience. Given the obesity problem in West Virginia, the massive interest of youth in social media, and the need for science projects relevant to student and community interest, the HSTA leadership designed a pilot study to test whether the combination of the HSTA infrastructure, college near-peer mentoring and social media curriculum were effective in addressing chronic health problems.

Obesity and Social Media. Over a third of children between the ages of 5 and 17 in the U.S. are overweight, and nearly $33 \%$ of those are obese (Lobstein et al., 2004). The increasing trend of obesity has leveled off for American youth; however, this overall success is disguising a widening disparity by socioeconomic status (SES). Those of higher SES are experiencing decreases in obesity rates, while the opposite is true for adolescents of lower SES (Frederick et al., 2014). This disparity is similar across racial and ethnic groups, and findings indicate at least a partial correlation between child obesity rates and parental educational attainment (Frederick et al., 2014). Further, rural children in the U.S. have 28\% greater odds of being obese than their urban peers (Johnson and Johnson, 2015). This relationship holds into adulthood, with obesity rates remaining significantly higher among rural adults compared to urban adults (Befort et al., 2012).

West Virginia has historically high numbers of adults who are overweight or obese (Bardwell et al., 2009), and has the highest obesity rate in the nation at $37.7 \%$ (Trust for America's Health and Robert Wood Johnson Foundation, 2017). The same is true for the state's adolescents, with obesity among high school students reaching its highest in a decade, increasing from $14.6 \%$ in 2011 to $15.6 \%$ in 2013 (Morrison, 2013) to $17.9 \%$ in 2015 (Trust for America's
Health and Robert Wood Johnson Foundation, 2015). West Virginians also have the highest rates of hypertension in the U.S, 42.7\% (Trust for America's Health and Robert Wood Johnson Foundation, 2015). Cholesterol levels are also higher, and while heart attack rates have decreased slightly, they remain higher than the national rate, as do stroke and diabetes, which have increased over the last decade (PHA PHA, 2012). These diseases in adulthood have been linked both to SES and a constellation of biomedical markers in childhood: high BMI, blood pressure and triglycerides, and low high-density lipoprotein (HDL) cholesterol (Langenbergy et al., 2006; Schreier and Chen, 2010). As obesity increases with age, the predictive ability of determining obesity in adulthood increases (Figueroa et al., 1993). Adolescence is the most physically robust period of the life course for most and is also the period when many habits will begin, including nutritional habits and physical activity levels. This makes adolescence a particularly important period to address overweight and obesity issues, as well as other health issues.

Individuals participating in obesity treatment programs have improved their health and adherence to program objectives by surrounding themselves with others who are working toward similar goals (Giannini et al., 2017). By establishing a support group, individuals can improve their health outcomes (Maidenberg, 2016). A 2013 scientific statement from the American Heart Association (AHA) reviewed the role of social networks and the use of social media approaches in childhood obesity prevention and management, and found that social media interventions can be used to build on existing social networks or to build new networks (Li et al., 2013). Further, Koehly and Loscalzo (2009) found that "by capitalizing on the structure of the network system, a targeted intervention that uses social relationships in families, schools, neighborhoods, and communities may be successful in encouraging healthful behaviors among children and their families" (p. 1). These networks of support, including parents, teachers, and friends, have been shown to be related to BMI and obesity-specific health-related quality of life (Herzer et al., 2011). Gow and colleagues (2010) found that first-year college students participating in an intervention that combined in-person interactions with an online component of support were able to achieve significant changes in BMI. The AHA statement notes that sites like Facebook are natural points for intervention because most (95\%) adolescents 12 to 17 years of age have Internet access, and most are active in online social media" (Lenhart et al., 2011; Li et al., 2013). They further note that such interventions "can also be used to provide specific content addressing healthy lifestyles with regard to diet and exercise....[and] "hold significant promise for application in the research setting because they are relatively inexpensive to scale up for broad implementation and can facilitate data collection" (Li et al., 2013). 


\section{METHODS}

The objective of the pilot intervention presented here was to determine if using social media curriculum, near-peer college mentors, and the HSTA infrastructure could impact the health of the adolescents served by the program which prepares minority, low-income, and rural high school students, many of whom will be the first in their families to attend college, for STEM fields (McKendall et al., 2000).

This study was done under West Virginia University IRB \# 1310116483. All investigators and high school participants were CITI trained.

Adult Oversight. Four HSTA faculty equivalents experienced in research and teaching high school were tasked with overseeing this project to ensure the safety of the participants. Their responsibilities included overseeing the student interactions throughout the intervention. They organized the mentor teams and maintained appropriate Facebook site content for both safety and liability. Together with leadership from a West Virginia University College of Physical Activity and Sports Science (CPASS) faculty, they encouraged mentor and mentee participation, and provided resources for mentors' questions. The CPASS faculty member led mentor training and monthly mentor meetings to discuss progress and solve problems.

Near-Peer College Mentor Description and Mentoring Framework. The social media curriculum for the intervention was delivered by 25 near-peer mentors that were selected from the West Virginia University Schools of Pharmacy, Medicine, Dentistry, Nutrition, and CPASS. These mentors, in groups of two, oversaw a Facebook group with an average of ten HSTA high school students.

Mentors were given a weekly schedule of Facebook interactions to follow, and were required to use an online class resource site to inform and to guide their weekly mentoring practices. The resource site synthesized all the resources for mentors to use throughout the program and was a space for mentors to post problems, comments, or concerns about their mentoring groups. Mentors checked this site for training information, weekly student message content, and guidelines about constructing a motivational message to post to their entire mentee group at the beginning of each week.

Mentors monitored individual student progress weekly and provided motivational comments based on each mentee's goals and progress. Additionally, they provided personal feedback for every mentee post and answered mentee posted questions. Statistics were kept on the amount of student involvement as well as the amount of mentor involvement. Mentors were tasked with ensuring high school students kept up a certain percentage of participation in the group, often reaching out to nonresponsive students asking them direct questions. HSTA and CPASS faculty monitored men- tors' work and also served as points of contact for challenges in mentor-mentee relationships. Mentors also monitored appropriateness of students' posts. While posts never needed to be deleted, a few posts needed to be redirected toward more positive thoughts to keep students on track. Additionally, there were several times that posts were made by students that were of a concerning nature, and HSTA faculty needed to contact the students' teachers and Field Site Coordinators to ensure the well-being of the student. This oversight was necessary to ensure not only faithfulness to the curriculum and pursuit of student goals, but also to ensure safety of all participants.

Mentor Curriculum Description. The curriculum the mentors used for the social media postings was built around the constructs of Bandura's Social Cognitive Theory, recognizing that determinants such as perceived self-efficacy, outcome expectations, goals, perceived facilitators and impediments all help translate knowledge of health behaviors into effective health practices (Bandura, 2004). While data were collected on these determinants, no significant differences were linked to the intervention. These data will not be included in this manuscript. Since the intervention was delivered online by mentors through Facebook, and there were no face-to-face meetings between students and mentors. The curriculum plan had to be broken down into small pieces of information that mentors could post to generate discussion and comments from group members. To help students increase their self-efficacy towards positive behavior change, the curriculum included posts to help students develop realistic goals and track progress towards those goals.

Mentor roles were to 1) motivate, 2) redirect students towards individual goals, 3) inspire, 4) celebrate success, 5) praise good behavior, 6) notice progress, 7) build cohesion in the group, 8) educate students on national health standards, 9) protect against legal and safety issues, 10) remove HIPAA violations, 11) connect with appropriate outside professionals and resources. They were to prevent 1) bullying, 2) undermining progress, 3) discussion of participant personal data, 4) discussion of prescriptive measures for an individual beyond national guidelines, 5) non-members on site, or 6) discussion of personal information about participants outside of the group.

Many of the posts led by the mentors focused on self-regulation skills, dispelling myths of exercise and diet programs, and helping students identify realistic expected outcomes while providing mentees with skills to cope with barriers to their set goals, as well as coping mechanisms to handle stress, and other emotional difficulties. Mentors posted a short message about the content for the week and then encouraged group members to post their experiences, tips or comments that were related. While the initial content in the intervention came from the mentors' posting the messages 
from the curriculum, the discussions and comments from group members were unscripted and provided helpful tips, stories and encouragement for everyone. The curriculum that was given to the mentors was modeled after the Diabetes Prevention Programs (US Department of Health and Humans Services, 2008) lifestyle intervention with similar messages and content adapted for delivery to high school students over social media. The messages were delivered weekly according to the schedule below. Brief descriptions are included for each week.

Week 1- Introductions

Week 2 - Remember Your Purpose - This week focused on helping students remember why they wanted to participate and what their goals were. Questions were posed to help students reflect on what they wanted to achieve.

Week 3 - Make Time for Yourself - Students were encouraged to make time to achieve the goals they set and set a weekly plan for them to work toward their goal.

Week 4 - Negative Thoughts - Examples of negative thoughts were shared with students as well as ways to practice positive thinking. Students were encouraged to respond to the group with thoughts they had about reaching their goals.

Week 5 - Boredom - This week gave students tips on ways to prevent boredom in their routine to work on their goals. Students were asked to share ways they deal with being bored with their plan.

Week 6 - Mental Gremlins/Slip Ups - Students were given examples of negative self-talk and ways to talk back to those thoughts. Tips were shared with students to combat mental gremlins.

Week 7 - Self-Regulation - The concept of self-regulation was introduced to the students. Questions were posed to the students to help them monitor their behavior and assess their outcomes in relation to their standards.

Week 8 - Ways to Stay Motivated - Motivational tips were shared with students. Students were also encouraged to add more tips that help them stay motivated.

Week 9 - What's your Pleasure? - Mentors asked students to comment on several things they enjoy doing but that they rarely do.

Week 10 - Social Cues - This week focused on helping students realize that they can be influenced by what other people do or say. The posts focused on helping students respond to those cues in positive ways or by helping students add helpful social cues.

Week 11 - Support - Students were asked to think and write about the people in their life that could support them in achieving their goals.

Week 12 - Problem Solving - Information about problem solving when faced with a challenge to their goal attainment was shared with the groups. The five steps of solving a problem were shared.
Week 13 - Excuses and Rationalizations - Mentors encouraged students to share a time when they heard themselves making excuses or rationalizations to do things that steer them away from their healthy lifestyles. Once the rationalizations and excuses were shared, students were encouraged to help other group members with new, healthier self-statements.

Week 14 - Give Yourself Some Credit - Students were congratulated on their hard work and asked to share their progress toward their goal. The group was asked to share three positive changes they made since beginning the program and they were encouraged to begin recording one or two things each day that they felt were creditworthy.

Week 15 - Staying Motivated on Holidays - Since the holidays were close to the timing of this post, students were reminded to stay on track with their goals. Mentors encouraged students to post ideas about how to maintain progress through the holidays.

Week 16 - Remember Your Purpose - This week focused on helping students remember why they chose their goal. This week's post was similar to the post in week 2 .

Week 17 - Slip Ups - Tips about what to do after a cheat or a slip up in students' goal plan were shared.

Week 18 - Ways to Stay Motivated - Since this post was already discussed, this week was a reminder of ways to stay motivated.

Week 19 - Staying on Plan during Holidays - This week had another holiday so students were again reminded about ways to stay on track during the holiday.

Week 20 - Support - Students were asked to post about other support systems they had in their quest to make a more healthy behavior change.

Week 21 - Weight and Diet-2 Components of Health Mentors posted information about components of health such as emotional, social, spiritual, intellectual and environmental health. Students were asked to share some of these factors in their life and how they influence their goals.

Week 22 - Social Health - Tips were shared with students on ways to improve their social health.

Week 23 - Intellectual Health - Tips were shared with students on ways to improve their intellectual health.

Week 24 - Give Yourself Some Credit - This week's posts were similar to Week 14. Since this week is close to the end of the program, students were reminded to think about what they are most proud of throughout their time in the program.

Week 25 - Self-Regulation - Students were asked to assess their outcomes and progress toward achieving their goals.

Week 26 - Maintenance - This week's post was all about how to maintain the new behaviors and lifestyle that the students worked toward throughout the year. Posts were directed toward helping students remember some of the lessons they learned throughout the program. 
Week 27 - Celebrate Your Progress - This was the final week of the program and students were asked to comment and reflect on the progress they had made since the beginning of the program.

High School Student Subjects. Participants represent a convenience sample of 134 11th grade students enrolled in a summer program hosted by HSTA. Some students knew each other because they came from the same high schools and a few others knew each other from previous summer camps, but for an entire week all participants lived together in dormitories at West Virginia University (WVU), dined together in the dining hall, participated in activities with each other and other classes, and attended daily courses taught by WVU faculty members. HSTA research coordinators obtained consent from 134 parents and assent for 134 adolescents in July 2014 and ensured the protection of Health Insurance Portability and Accountability Act standards. Participants received random identification numbers to protect their anonymity. See Table 1 for student demographics.

The role of HSTA student participants was to:

1. State their personal goal on the Facebook secret group site at the beginning of project. For example: I will work out 30 minutes a day, four days a week for seven months;

2. Post their activities relative to their personal goal on Facebook daily;

3. Encourage others who post their activities and goal progress;

4. Interact with other team members and mentors to Motivate, Model, and Inspire;

5. Work to meet their personal goal.

Initial Measurements and Goal Setting. Initial biomedical health assessments were taken at West Virginia University facilities where the summer camp was carried out and included weight, height, blood pressure, triglycerides, and fasting blood glucose. After receiving counseling about their results students were tasked with developing specific, meaningful, action-oriented, realistic, and timely (SMART) goals (Latham and Locke, 1991). Students recorded their goals into a survey through the secure, online survey and database application, REDCap (Harris et al., 2009). Study data were collected and managed using REDCap electronic data capture tools hosted at WVU. In the process, they learned that REDCap (Research Electronic Data Capture) is a secure, web-based application designed to support data capture for research studies, providing 1) an intuitive interface for validated data entry; 2) audit trails for tracking data manipulation and export procedures; 3 ) automated export procedures for seamless data downloads to common statistical packages; and 4) procedures for importing data from external sources. These open-ended goals were then categorized for analysis by program investigators into "weight loss," "exercise," "nu- trition," and "other" goals. "Other" goals included decreases or increases in specific biomedical measures (e.g., blood pressure). When respondents indicated more than one goal (e.g. "I want to lose weight by exercising more"), the first goal was categorized and analyzed. See Table 1 for details on goal categories. An Inter-Rater Reliability (IRR) analysis was performed to assess the degree that coders consistently assigned categories to subjects' open-ended goals. The resulting kappa indicated near perfect agreement between four

Table 1. Characteristics of All Students at First Screening by Goal Category

\begin{tabular}{|c|c|c|c|c|c|}
\hline & \multicolumn{4}{|c|}{ Goal Category } & $\mathbf{A l l}^{++}$ \\
\hline \multirow[t]{2}{*}{ Measure } & $\begin{array}{c}\text { Lose } \\
\text { Weight }\end{array}$ & Nutrition & Exercise & Other & $N=118$ \\
\hline & $\mathbf{N}=\mathbf{3 3}$ & $N=47$ & $N=\mathbf{2 4}$ & $N=14$ & \\
\hline
\end{tabular}

\begin{tabular}{|c|c|c|c|c|c|}
\hline \multicolumn{6}{|l|}{ Demographics } \\
\hline Female (\%) & 72 & 77 & 75 & 64 & 74 \\
\hline $\begin{array}{l}\text { African } \\
\text { American (\%) }\end{array}$ & 33 & 32 & 29 & 36 & 32 \\
\hline $\begin{array}{l}\text { Financially } \\
\text { Disadvantaged } \\
(\%) \\
\end{array}$ & 64 & 51 & 75 & 64 & 61 \\
\hline $\begin{array}{l}\text { First } \\
\text { Generation (\%) }\end{array}$ & 79 & 70 & 83 & 79 & 76 \\
\hline Rural (\%) & 67 & 77 & 83 & 71 & 75 \\
\hline \multicolumn{6}{|c|}{ Health Measures } \\
\hline BMI & $\begin{array}{l}30.40 \\
(5.19)\end{array}$ & $\begin{array}{l}23.86 \\
(5.53)\end{array}$ & $\begin{array}{l}26.64 \\
(6.08)\end{array}$ & $\begin{array}{l}24.87 \\
(6.31)\end{array}$ & $\begin{array}{l}26.35 \\
(6.20)\end{array}$ \\
\hline BMI z-score* & 1.74 & 0.7 & 1 & 0.79 & 1.07 \\
\hline
\end{tabular}

\begin{tabular}{lccccc}
\hline Overweight (\%) & 39 & 18 & 14 & 23 & $\mathbf{2 4}$ \\
\hline Obese (\%) & 51 & 13 & 38 & 23 & $\mathbf{3 0}$ \\
\hline Triglycerides & 93.43 & 78.38 & 85.55 & 68.07 & $\mathbf{8 2 . 5 7}$ \\
mean (SD) & $(92.45)$ & $(38.97)$ & $(52.46)$ & $(22.62)$ & $\mathbf{( 5 9 . 2 8 )}$ \\
\hline
\end{tabular}

\begin{tabular}{lccccc}
\hline $\begin{array}{l}\geq 110 \mathrm{mg} / \mathrm{dL}^{+} \\
(\%)\end{array}$ & 13 & 24 & 18 & 7 & $\mathbf{1 8}$ \\
\hline $\begin{array}{l}\text { Blood Pressure } \\
\text { mean (SD) }\end{array}$ & $\begin{array}{c}119 / 77 \\
(10 / 9)\end{array}$ & $\begin{array}{c}111 / 73 \\
(11 / 11)\end{array}$ & $\begin{array}{c}113 / 74 \\
(9 / 8)\end{array}$ & $\begin{array}{c}116 / 75 \\
(10 / 9)\end{array}$ & $\begin{array}{c}\mathbf{1 1 4} / 74 \\
(\mathbf{1 0} / \mathbf{1 0})\end{array}$ \\
\hline $\begin{array}{l}>120 / 80 \mathrm{mmHg}^{+} \\
(\%)\end{array}$ & 28 & 16 & 9 & 21 & $\mathbf{1 9}$ \\
\hline HDL mean (SD) & $\begin{array}{c}45.57 \\
(10.28)\end{array}$ & $\begin{array}{c}48.56 \\
(12.26)\end{array}$ & $\begin{array}{c}47.00 \\
(9.62)\end{array}$ & $\begin{array}{c}49.21 \\
(13.86)\end{array}$ & $\begin{array}{c}\mathbf{4 7 . 5 2} \\
(\mathbf{1 1 . 4 1})\end{array}$ \\
\hline
\end{tabular}

\begin{tabular}{lccccc}
\hline$<35 \mathrm{mg} / \mathrm{dL} L^{+}(\%)$ & 33 & 27 & 23 & 21 & $\mathbf{2 7}$ \\
\hline $\begin{array}{l}\text { Fasting Blood } \\
\begin{array}{l}\text { Glucose } \\
\text { mean(SD) }\end{array}\end{array}$ & $\begin{array}{c}92.00 \\
(44.08)\end{array}$ & $\begin{array}{c}86.17 \\
(10.02)\end{array}$ & $\begin{array}{c}90.29 \\
(11.60)\end{array}$ & $\begin{array}{c}82.38 \\
(9.06)\end{array}$ & $\mathbf{8 8 . 1 0}$ \\
\hline
\end{tabular}

$\begin{array}{llllll}\geq 100 \mathrm{mg} / \mathrm{dL} L^{+} & 4 & 2 & 5 & 0 & 3 \\ (\%)\end{array}$

${ }^{+}$Indicators of metabolic syndrome, ${ }^{++} 14$ Students did not specify a goal 
raters, $\kappa=0.90$ (Hallgreen, 2012).

Students were placed in 12 teams of between 9-12 students based on similar goals, and groups received a WVU student-mentor from the Sports Sciences, Nutrition, or Medicine fields. These near-peer college mentors went through a rigorous mentor certification program led by CPASS faculty. They were required to become certified as mentors before they were considered qualified to participate in this program.

After students returned to their communities from the summer program, teams and mentors worked together through weekly social media posts on private social media groups for 17 weeks. Mentors posted the weekly messages previously described and students responded.

Student Research Projects. Students and mentors were incentivized with the potential to earn up to $\$ 50$ for their participation. Because HSTA requires all students to work on a research project each year of the program, and research and statistical analysis skills are built into the learning process of the HSTA experience, the opportunity for students to be a part of the data collection and use the data for their own study was an additional incentive. To use the data, a student had to actively post at least $30 \%$ of the weeks, and be present for both the initial and follow-up screenings. At the inception of the intervention, students selected different research questions to focus their analysis. These questions ranged from determining if there were changes in weight, blood pressure, or cholesterol from the pre-assessment to the post-assessment; determining if there were differences in the aforementioned measures by gender or by rate of participation in the study; and distinguishing between changes in some of the behavioral assessments from the pre assessment to the post assessment. Once all the data were collected, students received the de-identified data set back from the study organizers to analyze the data as it related to their particular research question. Once students' data analysis was completed, the results were shared through HSTA's annual Research Symposium.

Private Facebook groups organized by goals did not have equal student participation for a multitude of reasons, starting with an uneven number of students choosing a particular goal. Some mentor attrition occurred as well, so groups were consolidated over the course of the project to maintain an active level of participation.

Final Measurements. Post-intervention screenings occurred seven months after the initial screening. HSTA encouraged participants to return to WVU for follow-up screenings by providing free chartered buses and promoting it as an opportunity to connect with their friends from camp. All measures were repeated at follow-up to provide complete health profiles to students at both times. Students fasted for 12-hours before screening and self-reported their height (without shoes) while weight was measured with shoes and socks removed. BMI was calculated using weight and height then converted to standardized z-scores using Centers for Disease Control and Prevention (CDC) sex, age and height specific charts. BMI was categorized based on criterion established by the Childhood Obesity Working Group, allowing for comparisons across age and sexes over time while accounting for extreme values (Vidmar et al., 2004; Wang et al., 2015). Blood pressure was taken up to three times averaged if more than once - using a manual cuff with a sphygmomanometer. Blood was drawn with a finger stick and analyzed using a Cholestech machine on site.

Statistical Analysis. From the initial group of 134 students, 16 students' data was removed. These 16 represented extreme outliers and those missing any height or weight information. Descriptive statistics were examined for all measures, including distributions. Independent t-tests and chi-square tests were used to compare the 57 students who participated in follow-up screenings to those who did not on all measures taken at the initial screening and by group participation. Depending on the distribution of the outcome, paired t-tests and the sign test were used to identify differences in pre- and post-health measures within each goal category. One-way ANOVAs were used to examine variations in changes in health measures between goal categories. Posthoc Bonferroni analyses were used to clarify differences between groups further.

\section{RESULTS}

Of the original 134 students who were consented, 16 were extreme outliers or missing complete or accurate information on height and weight and were excluded from statistical analyses. Because the data are so revealing of the plight of under-represented youth in West Virginia, the results of the remaining 118 students' initial health screenings are provided (Table 1). Only 57 students from the original 118 returned for the follow up. Their data were analyzed separately (Table 2).

Of the original 118 students, the average BMI of students was $26.35 \mathrm{lb}$./in.2, and less than half of the students (40.7\%) had a healthy BMI, with $30 \%$ of students obese, and $24 \%$ overweight (Table 1). Further, 18\% of students had high triglycerides, $19 \%$ of students had high blood pressure, nearly a third (27\%) had low levels of healthy cholesterol (HDL), and $3 \%$ of participants had high levels of fasting blood glucose.

Those fifty-seven who participated in follow-up used social media significantly more than those who did not return (an average of 44 times compared to 14$)(\mathrm{t}=-4.40, \mathrm{df}=118$, $\mathrm{P}<.01)$. Follow-up participants were $71 \%$ female, $41 \%$ African American, 74\% rural, 60\% financially disadvantaged, 
$74 \%$ first-generation college students, with an average age of 16.7 years. Chi-square tests determined that students who attended the follow-up did not significantly differ on measures of sex, race, SES, or geography. Comparing pre- and post-health screening results (Table 2) for those who participated in both, significant shifts occurred in the percentage of individuals in the overweight and obese categories, from $15.8 \%$ to $22.8 \%$ and from $29.8 \%$ to $24.6 \%$, respectively. Slight decreases occurred in BMI z-scores (from the 87th to the 79th percentile) and mean levels of HDL cholesterol.

The most significant differences in health measures pre- and post-social media intervention occurred within the groups that selected weight loss and nutrition as their goals. The Sign test indicated the weight loss goal group showed significant differences in average pre- and post-BMI z-scores $(\mathrm{P}=.04)$, which was further supported through the results of a paired $\mathrm{t}$-test $\left(\mathrm{t}^{*}=-2.89, \mathrm{CI}=-0.45--0.07, \mathrm{P}=.01\right) . \mathrm{HDL}$ cholesterol levels significantly increased at the post-screening $(\mathrm{P}=.05)$ for all participants; however, when analyzed by goal category, significant change only held for those who chose improving nutrition as a goal $(\mathrm{P}=.05)$.

A one-way ANOVA provided evidence that mean BMI $\mathrm{z}$-scores at the first screening differed between at least two goal categories $(\mathrm{F} 3,99=7.22, \mathrm{P}<.001)$. Post-hoc Bonferroni tests confirmed a significant difference between those students that chose weight loss as their goal, and those who selected "physical activity" $(\mathrm{P}=.05)$, "nutrition" $(\mathrm{P}<.001)$ or "other" $(\mathrm{P}=.02)$ goals; however, no significant differences between any of the other goals were demonstrated. Importantly, all BMIs in the other categories were below the 85th percentile on the $\mathrm{CDC} / \mathrm{WHO}$ growth charts. Participants who selected a weight loss goal had BMIs ranging from $21.90 \mathrm{lb}$./in. 2 to $40.31 \mathrm{lb}$./in. 2 and BMI z-scores from .45 (67th percentile) to 2.59 (99.5th percentile). Only 4 of 29 of students with a weight loss goal had a BMI z-score $\leq$ 85 th percentile.

\section{DISCUSSION}

Currently STEM enrichment programs are common but rarely do they deliver STEM enriched curriculum intended to 1) teach the process of research 2) teach behavior change process and 3) measure health outcomes to detect behavior change. In this case, a student requirement to participate in a research project was the foundation for this pilot. Within this foundation, STEM enriched curriculum was delivered to 134 students around behavior change. The students personally experienced the behavior change model throughout the intervention. Health measures were taken before and after, giving the leaders the ability to evaluate the impact while the most active participants were able to use the data for their own research question. It is a bonus that all participants were able to actively try a behavior change approach personally
Table 2. Pre- and Post-Intervention Results for All Participating in Follow-up and by Weight Loss Goal

\begin{tabular}{|c|c|c|c|c|}
\hline \multirow[b]{2}{*}{ Health Measures } & \multicolumn{2}{|c|}{ All Goals (n=57) } & \multicolumn{2}{|c|}{ Weight Loss Goal $(n=29)$} \\
\hline & Pre & Post & Pre & Post \\
\hline BMI, mean (SD) & $25.76(5.69)$ & $25.54(5.62)$ & $29.25(5.52)$ & $28.39(5.84)$ \\
\hline $\begin{array}{l}\text { BMI z-score, mean } \\
\text { (SD) }\end{array}$ & $.95(1.07)$ & $.81(1.12)^{*}$ & $1.57(.67)$ & $1.32(.90)^{*}$ \\
\hline BMI percentile & $87^{\text {th }}$ & $79^{\text {th }}$ & $94^{\text {th }}$ & $91^{\text {st }}$ \\
\hline \multicolumn{5}{|l|}{ BMI Category } \\
\hline Overweight (\%) & 15.8 & $22.8 * * *$ & 26.7 & $20.0 * *$ \\
\hline Obese (\%) & 29.8 & $24.6^{* * *}$ & 53.3 & $46.7 * *$ \\
\hline $\begin{array}{l}\text { Triglycerides, } \\
\text { mean (SD) }\end{array}$ & $\begin{array}{c}74.28 \\
(41.10)\end{array}$ & $\begin{array}{c}69.43 \\
(41.73)\end{array}$ & $\begin{array}{c}77.73 \\
(53.13)\end{array}$ & $\begin{array}{c}80.86 \\
(47.09)\end{array}$ \\
\hline$\geq 110(\%)$ & 15.8 & 8.9 & 13.3 & 13.3 \\
\hline $\begin{array}{l}\text { Blood Pressure, } \\
\text { mean (SD) }\end{array}$ & $\begin{array}{l}114 / 74 \\
(11 / 11)\end{array}$ & $\begin{array}{l}116 / 74 \\
(10 / 9)\end{array}$ & $\begin{array}{l}119 / 76 \\
(11 / 10)\end{array}$ & $\begin{array}{l}118 / 78 \\
(13 / 9)\end{array}$ \\
\hline$\geq 120 / 80(\%)$ & 22.4 & 12.1 & 31.3 & 25 \\
\hline HDL, mean (SD) & $\begin{array}{c}48.95 \\
(12.66)\end{array}$ & $\begin{array}{c}50.55 \\
(12.66)^{*}\end{array}$ & $45.60(11.4)$ & $\begin{array}{c}48.47 \\
(14.55)\end{array}$ \\
\hline$<35 \mathrm{mg} / \mathrm{dL}(\%)$ & 23.6 & 21.8 & 28.6 & 28.6 \\
\hline $\begin{array}{l}\text { Fasting Blood Glu- } \\
\text { cose mean (SD) }\end{array}$ & $\begin{array}{c}86.32 \\
(10.71)\end{array}$ & $87.22(8.95)$ & $\begin{array}{c}84.21 \\
(14.45)\end{array}$ & $90.27(6.86)$ \\
\hline$\geq 100 \mathrm{mg} / \mathrm{dL}(\%)$ & 2.1 & 2.1 & 0 & 0 \\
\hline
\end{tabular}

while learning what it is as they reach for better health.

This innovative study is driving directly at the fact that we know "more education" correlates with "better health" (US Department of Health and Humans Services, 2011). An often cited reason for disparities is lack of access to health care. This pilot study exemplifies a more personalized education, directly impacting behavior and improving health outcomes in a hard to reach population. The results are important because this population suffers from health disparities linked to poor access to health care and the consequences of unhealthy lifestyles and environment.

This pilot study examines the influence of a social media curriculum intervention on childhood obesity in a group of minority, low-income, rural students. The intervention examines the impact of meaningful health and wellness goals paired with a near-peer mentor social support network. Using social media and mentors, we found a significant positive influence on two biometric measures: BMI and HDL cholesterol. This result confirms the importance of a social support group involving participants with similar goals when trying to improve one's health.

The $30 \%$ prevalence of obesity among the HSTA students in this sample is twice that of rates reported for children in the U.S (Gurka et al., 2012) and what the Youth Behavioral 
Risk Factor Surveillance System reported for West Virginia as a whole in 2013 the same year of this study. Similarly, whereas the average BMI z-score for children aged $12-19$ calculated from 1999 - 2010 ranged from 0.5 to 0.6 (Gurka et al., 2012), among this group of HSTA students it was 1.1. The same data indicates a lower average trend of blood pressure levels among a large U.S. sample compared to the students in the current study (Gurka et al., 2012). Additionally, HDL cholesterol is lower for the HSTA students at follow-up than those presented from the U.S. sample (Gurka et al., 2012). Insofar as childhood health predicts adult health, the profile of this group foreshadows grave consequences for the cohort as they age, demonstrating the importance of cross-sectoral health investment and the use of technology (i.e. social media), embedded within a STEM enrichment program targeting disadvantaged adolescents.

In a study where eight randomized controlled trials were combined in a meta-analysis of social network platforms including Facebook, a positive effect of social network interventions on health behavior outcomes was found (Laranjo et al, 2014). In the field of HIV, social media was useful in influencing behavior change in hard to reach populations (Latkin and Knowlton, 2015). Both studies recommended further research. In this study, the flexibility of social media to reach and build a support team for students across distances in rural areas was the impetus behind the intervention design. Social media is an inexpensive platform to provide mentoring and social support to rural students. It connects students from diverse backgrounds and regions with common issues relevant to themselves and their communities and allows students many miles from each other to interact under the supervision of college mentors and adults, independent of time and place. This format could increase access to health information, improve health literacy in hard to reach populations, and provide or increase access to social support for healthy lifestyles, particularly in rural areas.

This study is not without limitations. The students involved are over-representative of the disadvantaged in West Virginia and represent a limited age range. Half of the students did not follow-up, and some of the groups were combined to assist active students who were in an inactive group. Mentor attrition also occurred; thus, mentors were not always the same across the course of the study. Due to students choosing multiple goals or non-SMART goals, study investigators had to determine their category assignments for final analysis. When students indicated more than one goal, the first goal was categorized and analyzed. Additionally, if the goals were not presented in SMART format, the general theme of the goal was categorized. While increasing physical activity and improving nutrition were SMART goals, the study design did not include these intermediary measures for analysis. Despite the complexity of the project, there are important outcomes. It is evident that much work needs to be done to address the health and wellness of disadvantaged high school students.

STEM outreach is potentially a way to improve the health of students as it improves diversity in workforce development. The success of HSTA in STEM workforce development in under-represented populations is well documented (McKendall et al. 2014). The ability of HSTA to reach underserved youth to promote healthy living has been suspected but not documented until now. The importance of this study is the demonstration that a successful STEM outreach program is able to provide a mechanism to improve health even though its mission is to recruit under-represented students into the STEM careers. If this is true for this particular STEM outreach program, the potential may be there for other STEM outreach programs as well.

In addition to demonstrating the potential benefits of an education-based, health promotion intervention targeting disadvantaged adolescents, this study provides an important health profile of a group of teens from a rural region in the U.S. The results of the initial screening provide the health profile of a group of predominantly rural $(75 \%)$, disadvantaged high school students drawn from nearly half of West Virginia counties. The health profile of this group of students mirrors the health concerns seen in West Virginia, with many of the risk factors at higher levels for adolescents in the current study. This region has some of the lowest life expectancies (Institute for Health Metrics and Evaluation, 2015) and highest rates of risk factors for cardiovascular disease and diabetes. Given the monumental health disparities between West Virginia and U.S. adolescents, we need to consider effective platforms for encouraging these students to become more health conscious. This study's data can be used to measure the impact of interventions and guide practitioners and policy makers toward implementing prevention programs targeting adolescents.

In this study, a potential next question might be: is the delivery through peer and/or near-peer mentoring the key to its success or is it the personal goal framework in which the curriculum is delivered? Collaboration between after-school programming for high school students and universities training health professionals offer an opportunity to test this. Health professions students in schools of medicine, dentistry, pharmacy, nursing, and public health often have community service requirements and community engaged research requirements. In further research, a comparison of outcomes could be tested where one group of high school students receives STEM content around personal goals with college mentors, another has just the STEM content and the mentors, and a third group has just the STEM content. Teasing out the importance of mentors from the importance of personal goals in STEM enrichment curriculum may provide an important key to prevention of chronic disease globally among adolescents beyond the tradition of educating them in prevention. 


\section{AUTHOR INFORMATION}

\section{Corresponding Author}

WV

Ann Chester, West Virginia University, Morgantown,

achester@hsc.wvu.edu

\section{Author Contributions}

The manuscript was written through contributions of all authors. All authors have given approval to the final version of the manuscript.

\section{FUNDING SOURCES}

The Claude Worthington Benedum Foundation supported this work.

\section{ABBREVIATIONS}

STEM: Science, technology, engineering, math; HSTA: Health Sciences and Technology Academy; WVU: West Virginia University; SES: Socioeconomic status; HDL: high-density lipoprotein; AHA: American Heart Association; BMI: Body mass index; CPASS: College of Physical Activity and Sports Science; HIPAA: Health Insurance Portability and Accountability Act; SMART: Specific, meaningful, action-oriented, realistic, timely; REDCap: Research Electronic Data Capture; IRR: Inter-Rater Reliability; CDC: Centers for Disease Control; WHO: World Health Organization; SD: Standard deviation; HIV: Human Immunodeficiency Virus

\section{REFERENCES}

Bandura, A. (2004). Health promotion by social cognitive means. Health Education Behavior, 31(2), 143-164

Bardwell, G., Morton, C., Chester, A., Pancoska, P., Buch, S., Cecchetti, A., Vecchio, M., Paulsen, S., Groark, S., Branch, R.A. (2009). Feasibility of adolescents to conduct community based participatory research on obesity and diabetes in rural Appalachia. Clinical and Translational Science, 2(5), 340-349.

Befort, C.A., Nazir, N., and Perri, M.G. (2012). Prevalence of obesity among adults from rural and urban areas of the United States: findings from NHANES (2005-2008). The Journal of Rural Health, 28(4), 392-397.

Buijs, M. and Admiraal, W. (2013) Homework assignments to enhance student engagement in secondary education. European Journal Psychological Education. 28(3), 767-77

Brown, J. L., Collins, A., and Duguid, P. (1989). Situated cognition and the culture of learning. Educational Researcher, 18(1), 32-42.

Chester, A. and Dooley, E. (2011). West Virginia University's Health Sciences and Technology Academy. Journal of Higher Education Outreach and Engagement, 15(3) 87-99
Cothorn J.H., Giese,R.N., and Rezba, R.J. (2006). Students and research: Practical strategies for science classrooms and competitions. Dubuque, Iowa: Kendall/Hunt Pub. Co. Chicago

Figueroa-Colon, R., von Almen, T.K., and Suskind, R.M. (1993). Treatment of childhood obesity. In RM Suskind and L Lewinter-Suskind (Eds.), Textbook of pediatric nutritions (2nd ed. Pp. 285-293) New York: Raven Press.

Frederick, C.B., Snellman, K., and Putnam, R.D. (2014). Increasing socioeconomic disparities in adolescent obesity. Proceedings of the National Academy of Sciences, 111(4), 1338-1342.

Giannini, C.M., Irby, M.B., Skelton, J.A., and Gesell, S.B. (2017). Feasibility of a friendship network-based pediatric obesity intervention. Childhood Obesity, 13,18-24.

Gow, R.W., Trace, S.E., and Mazzeo, S.E. (2010). Preventing weight gain in first year collect students: an online intervention to prevent the "Freshman Fifteen." Eating Behaviors, 11(1), 33-39.

Gurka, M.J., Ice, C.L., Sun, S.S., and DeBoer, M.D. (2012). A confirmatory factor analysis of the metabolic syndrome in adolescents: an examination of sex and racial/ethnic differences. Cardiovascular Diabetology, 11(1), 1-10.

Hallgren, K.A. (2012). Computing inter-rater reliability for observational data: An overview and tutorial. Tutorials in Quantitative Methods for Psycholology, 8(1), 23-34.

Harris, P.A., Taylor, R., Thielke, R., Payne, J., Gonzalez, N., Conde, J.G. (2009). Research electronic data capture (REDCap) A metadata-driven methodology and workflow process for providing translational research informatics support, Journal of Biomedical Information. 42(2), 377-381.

Herzer, M., Zeller, M.H., Rausch, J.R. (2011). Modi, A.C. Perceived social support and its association with obesity-specific health-related quality of life. Journal of Developmental and Behavioral Pediatrics, 32(3), 188-195.

Institute for Health Metrics and Evaluation. (2015). Data and tools. Retrieved from http://www.healthdata.org/us-county-profileshttp://www.healthdata.org/data-tools.

Johnson, J.A., and Johnson, A.M. (2015). Urban-rural differences in childhood and adolescent obesity in the United States: A systematic review and meta-analysis. Childhood Obesity, 11(3), 233-241.

Kindness and Cruelty on Social Newworking Sites. Washington, D.C.: Pew Research Center.

Koehly, L.M., and Loscalzo, A. (2009). Adolescent obesity and social networks. Preventing Chronic Disease, 6(3), A99

Langenberg, C., Kuh, D., Wadsworth, M.E., Brunner, E., and Hardy, R. (2006). Social circumstances and education: life course origins of social inequalities in metabolic risk in a prospective national birth cohort. American Journal of Public Health, 96(12), 2216-2221.

Laranjo, L., Arguel, A., Neves, A.L., Gallagher, A.M., Kaplan, R., Mortimer, N., Mendes, A.G., and Lau, A.Y.S. (2015). The influence of social networking sites on health behavior change: a systematic review and meta-analysis, Journal of the American Medical Informatics Association, 22(1) 243-256. 
Latkin, C. A., and Knowlton, A. R. (2015). Social Network Assessments and Interventions for Health Behavior Change: A Critical Review. Behavioral Medicine (Washington, D.C.), 41(3), 90-97.

Latham, G.P., and Locke, E.A. (1991). Self-regulation through goal setting. OrganizationalBehavior and Human Decision Processes, 50(2), 212-247.

Lenhart, A., Madden, M., Smith, A., Purcell, K., Zickuhr, K., and Rainie, L. (2011). Teens,

Li, J.S., Barnett, T.A., Goodman, E., Wasserman, R.C., and Kemper, A.R. (2013). Approaches to the prevention and management of childhood obesity: The role of social networks and the use of social media and related electronic technologies. Circulation, 127(2), 260-267.

Lobstein, T., Baur, L., and Uauy, R. (2004). IASO International Obesity TaskForce: Obesity in children and young people: a crisis in public health. Obesity Reviews, 5(Suppl 1:4), 104 .

Maidenberg, M.P. (2016). Childhood, adolescent, and teenage obesity: Recommendations for community initiative in Central Harlem. National Association of Social Workers, 85-91.

McKendall, S.B., Simoyi, P., Chester, A.L., and Rye, J.A. (2000). The Health Sciences and Technology Academy: Utilizing pre-college enrichment programming to minimize post-secondary education barriers for underserved youth. Academic Medicine, 75(10), S121-S123.

Morrison, C. (2015). 2013 West Virginia youth risk behavior survey results of High School students. West Virginia Department of Education Office of Research.

National Acadmemy of Sciences. (2015). Identifying and supporting STEM programs in out-of-school settings. Washington, D.C.: The National Academies Press.

PHA PHA. (2012). 2012 West Virginia state health profile shaping safe and healthy communities. West Virginia: West Virginia Department of Health and Human Resources.

Schreier, H.M.C., and Chen, E. (2010). Socioeconomic status in one's childhood predicts offspring cardiovascular risk. Brain Behavior and Immunity, 24(8),1324-1331.

Siciliano, P.L., Hornbeck, B.L., Hanks, S., Kuhn, S., Zbehlik, A.J., and Chester, A.L. (2018). Taking a look at the Health Science and Technology Academy (HSTA). Journal of STEM Outreach, 1(1).

Trust for America's Health and Robert Wood Johnson Foundation. (2017). Adult obesity in the United States. Retreived from https://stateofobesity.org/adult-obesity/.

Trust for America's Health and Robert Wood Johnson Foundation. (2015). States with the Highest Hypertension Rates. Retrieved from https://stateofobesity.org.

Trust for America's Health and Robert Wood Johnson Foundation. (2015). Study of high school students. Retrieved from https://stateofobesity.org.

US Department of Health and Human Services. (2008). Diabetes Prevention Program (DPP). Retrieved from https://www. niddk.nih.gov/about-niddk/research-areas/diabetes/diabetes-prevention-program-dpp/Documents/DPP_508.pdf
US Department of Health and Human Services. (2011). Health, United States, 2011, with special feature on socioeconomic status and health. Retrieved from https://www.cdc.gov/ nchc/data/nus/hus11.pdf

Vidmar, S., Carlin, J., Hesketh, K., and Cole, T. (2004). Standardizing anthropometric measures in children and adolescents with new functions for egen. Stata Journal, 4(1), 50-55.

Wang, M.T., Degol, J., and Ye, F. (2015). Math achievement is important, but task values are critical, too: Examining the intellectual and motivational factors leading to gender disparities in STEM careers. Frontiers in Psychology, 6. Article 36, 1-9 